\title{
A mixture of the aqueous extract of Garcinia cambogia, soy peptide and L-carnitine reduces the accumulation of visceral fat mass in rats rendered obese by a high fat diet
}

\author{
Yun Jung Kim · Keun-Young Kim • Min Sun Kim • \\ Jin Hee Lee · Kang Pyo Lee · Taesun Park
}

Published online: 17 November 2007

(C) Springer-Verlag 2007

\begin{abstract}
The aim of the present study was to investigate the anti-obesity effect of a mixture composed of Garcinia cambogia extract, soypeptide, and L-carnitine (1.2:0.3:0.02, $\mathrm{w} / \mathrm{w} / \mathrm{w}$ ) in rats rendered obese by a high-fat diet (HFD). Sprague-Dawley rats were fed either the high-fat control diet (CD) or the $0.38 \%$ mixture-supplemented HFD $(\mathrm{CD}+\mathrm{M})$ for 9 weeks. The mixture significantly reduced body weight gain and the accumulation of visceral fat mass in a rat model of HFD-induced obesity. Moreover, the mixture effectively lowered blood and hepatic lipid concentrations and serum glucose, insulin, c-peptide, and leptin levels in rats with HFD-induced obesity. Results from real-time reverse transcription-polymerase chain reaction analyses indicated that the expression levels of leptin, tumor necrosis factor-alpha (TNF- $\alpha)$, and sterol regulatory element binding protein 1c (SREBP1c) genes in the epididymal fat tissue of rats fed the $\mathrm{CD}+\mathrm{M}$ diet were 0.4-, 0.6-, and 0.48-fold, respectively, of those found in the $\mathrm{CD}$ rats $(P<0.05)$, while expression of the uncoupling protein 2 (UCP2) gene in epididymal adipose tissue was 1.25 -fold $(P<0.05)$ of that found in CD rats. In conclusion, a mixture composed of G. cambogia extract, soy peptide, and L-carnitine attenuated visceral fat accumulation and improved dyslipidemia in a rat model with HFDinduced obesity.
\end{abstract}

Y. J. Kim · K.-Y. Kim · T. Park ( $₫)$

Department of Food and Nutrition, Brain Korea 21 Project,

Yonsei University, 134 Shinchon-dong, Sudaemun-ku,

Seoul 120-749, South Korea

e-mail: tspark@yonsei.ac.kr

M. S. Kim - J. H. Lee - K. P. Lee

CJ Foods R\&D, Seoul 152-050, South Korea
Keywords Garcinia cambogia - Soypeptide . L-carnitine - Anti-obesity effect .

High-fat-diet-induced obesity rats · Obesity-related genes

\section{Introduction}

Obesity is one of the most serious and the fastest growing public health problems throughout the industrialized world. Obesity, especially with visceral fat accumulation, is a serious risk factor for so-called metabolic syndrome, which includes insulin resistance, glucose intolerance, hypertension, and dyslipidemia [28]. The recent epidemic increase in obesity in developed countries points to the important interaction between genes that predispose to obesity and environmental factors that facilitate expression of the obese phenotype, a trait shared with high-fat diet (HFD)-induced obesity rodent models [8].

Studies on obesity in the field of food science have focused on the search for functional food ingredients and/or herbal extracts that can suppress the accumulation of body fat. Some herbal products and plant extracts, such as Semen Cassiaem [23], Panax ginseng berry extract [4], Singiber officinale Roscoe [18], and Platycodi radix [17], have been shown to exert anti-obesity effects in rodents with HFDinduced obesity. Anti-obesity food ingredients and herbal extracts may also prevent lifestyle-related diseases, if they are effective in reducing body fat accumulation.

Garcinia cambogia, an edible fruit native to southeastern Asia, contains large quantities of hydroxy citric acid (HCA), which has been shown to inhibit ATP citrate lyase (EC 4.1.3.8) [34], suppress de novo fatty acid synthesis and food intake, and consequently decrease body weight gain [20]. Several studies in animals and humans have shown that consumption of soybean has beneficial effects in a 
variety of disorders including hypocholesterolemia, cardiovascular disease, renal disease, bone resorption, certain forms of cancer, and obesity [2, 7, 37]. Soy protein or peptide has been thought to be responsible for the cholesterol-lowering effect of soybean $[3,13]$. L-Carnitine $(\beta$ hydroxy- $\gamma$-trimethylaminobutyric acid) is a small, watersoluble, quaternary amine that is responsible for maintaining the energy metabolism in mammals as an essential cofactor in the transport of long-chain fatty acids across the inner mitochondrial membrane for subsequent fat degradation and energy production [35].

The present study was conducted to test our hypothesis that metabolic changes induced by a mixture of G. cambogia, soy peptide, and L-carnitine are associated with a reduction in HFD-induced adiposity, especially visceral fat mass, in rats. To provide a possible scientific basis for the extensive usage of these three functional food ingredients, we investigated their effects as a mixture on visceral fat mass, lipid profiles in the serum and liver, and serum adipocytokine levels. Mixture-induced regulation of the expression of multiple adipose tissue genes was evaluated in rats rendered obese by a high-fat diet.

\section{Materials and methods}

\section{Animals and diets}

Five-week-old male Sprague-Dawley rats ( $n=20$, Orient Co, Seoul, Korea) were individually housed in stainless steel rat cages in a room where the temperature was kept at $21 \pm 2.0^{\circ} \mathrm{C}$, the relative humidity was kept at $50 \pm 5 \%$, and the light was maintained on a $12 \mathrm{~h}$ light/dark cycle. All the rats consumed a commercial diet and tap water ad libitum for 1 week prior to their allocation to one of two weight-matched groups: the high-fat control diet group (CD) and the mixture-supplemented HFD group (CD + $\mathrm{M})$. The CD was based on the AIN-76 rodent diet composition and contained $200 \mathrm{~g}$ fat $/ \mathrm{kg}$ (170 g lard plus $30 \mathrm{~g}$ corn oil) and $1 \%$ cholesterol by weight. The HFD was formulated to provide $40 \%$ of the total energy generated by the diet from fat, by replacing carbohydrate energy with lard and corn oil, and had the same amount of vitamins and minerals per kilojoule as the normal diet. The $\mathrm{CD}+\mathrm{M}$ was identical to the CD but additionally contained $0.38 \%$ mixture composed of G. cambogia extract (InterHealth Co, Benicia, CA; containing 60\% HCA), soy peptide (Fuji Oil Co, Ibaraki, Japan) and L-carnitine (Lonza, Basel, Switzerland) in the proportion of 1.2:0.3:0.02 (w/w/w). The diets were given in the form of pellets for 9 weeks.

This study adhered to the Guide for the Care and Use of Laboratory Animals developed by the Institute of Laboratory Animal Resources of the National Research Council, and approved by the Institutional Animal Care and Use Committee of Yonsei University in Seoul, South Korea.

Lipid analyses

Serum concentrations of total cholesterol, HDL cholesterol, triglyceride (Young-dong Diagnostics, Seoul, Korea), and free fatty acid (Eiken Chemical, Tokyo, Japan) were determined enzymatically using commercial kits. The serum VLDL + LDL cholesterol concentration was calculated by subtracting the concentration of HDL cholesterol from the total cholesterol concentration.

Hepatic lipids were extracted as described previously [12], and the dried lipid residues were dissolved in $1 \mathrm{ml}$ ethanol. The concentrations of cholesterol and triglycerides in hepatic lipid extracts were measured using the same enzymatic kits used for the serum lipid analyses.

Serum insulin, adipocytokines and glucose assays

Serum insulin, c-peptide, and leptin levels were measured by radioimmunoassay (RIA rat insulin, rat c-peptide, and rat leptin kits; Linco Research, St. Charles, MO). The serum glucose concentration was determined using an automatic analyzer (Express Plus, Chiron Diagnostics, Emeryville, CA) with reagents from Bayer (Leverkusen, Germany).

\section{Real-time PCR}

Total RNA was isolated from the epididymal fat tissues of each rat using Trizol (Invitrogen, Carlsbad, CA), according to the manufacturer's instructions. The quantity and quality of the RNA samples was assessed using a Optima TLX-120 spectrophotometer (Beckman, Fullerton, CA) and an Agilent 2100 bioanalyzer (Agilent Technologies, Wilmington, DE).

Primers for real-time PCR analysis were designed using the Whitehead Institute/MT Center for Genome Research's Primer3 interface, which is available online. The sequences of the designed primers were as follows: leptin- sense-5'-CACAGAGGTGGTGGCTCTGA-3' and antisense-5'-CCCGGTGGTCTTGGAAACTT-3'; tumor necrosis factor $\alpha(\mathrm{TNF} \alpha)$-sense- $5^{\prime}$-AGATCATCTTCTCA AAACTC- $3^{\prime}$ and antisense-5'-TAAGTACTTGGGCAGG TTGA-3'; resistin- sense-5'-ACTTCAGCTCCCTACTG CCA- $3^{\prime}$ and antisense- $5^{\prime}$-GCTCAGTTCTCATCAATCAA CCGTCC-3'; sterol-regulatory-element-binding protein-1c (SREBP1c)- sense-5'-GGAGCCATGGATTGCACATT$3^{\prime}$ and antisense- $5^{\prime}$-AGGAAGGCTTCCAGAGAGGA-3'; 
peroxisome proliferators' activated receptor $\gamma 2$ (PPAR $\gamma 2)$ sense-5'-CTTGGCCATATTTATAGCTGTCATTATT-3' and antisense- $5^{\prime}$-TGTCCTCGATGGGCTTCAC- ${ }^{\prime}$; CCAAT/ enhancer-binding protein $\alpha(\mathrm{C} / \mathrm{EBP} \alpha)$ - sense-5'-GGCGG GAACGCAACAA- $3^{\prime}$ and antisense-5'-TCCACGTTGCG CTGTTTG- ${ }^{\prime}$; uncoupling protein 2 (UCP2)- sense- $5^{\prime}$-AC AAGACCATTGCACGAGAG- $3^{\prime}$ and antisense- $5^{\prime}$-CATG GTCAGGGCACAGTGGC- $3^{\prime}$; and $\beta$-actin- sense- $5^{\prime}$-ACC TTCAACACCCCAGCCATGTACG- $3^{\prime}$ and antisense- $5^{\prime}$ CTGATCCACATCTGCTGGAAGGTGG- $3^{\prime}$.

Total RNA $(1 \mu \mathrm{g})$ was reverse-transcribed using a Superscript II kit (Invitrogen), according to the manufacturer's recommendations. Real-time PCR reactions were then carried out in a $20 \mu \mathrm{l}$ reaction mixture $(2 \mu \mathrm{l}$ cDNA; $16 \mu \mathrm{l}$ SYBR Green PCR Master Mix, which includes $2 \mu \mathrm{l}$ $1 \times$ LightCycler; $2.4 \mu \mathrm{l} 1.5 \mathrm{mM} \mathrm{MgCl}{ }_{2}$ and $11.6 \mu \mathrm{H}_{2} \mathrm{O}$; and $1 \mu \mathrm{l}$ of a $0.5 \mu \mathrm{mol} / \mathrm{l}$ specific gene primer pair solution) in a LightCycler (Roche Diagnostics, Basel, Switzerland). The PCR program was initiated with a 10 min reaction at $95^{\circ} \mathrm{C}$ before 40 thermal cycles of $10 \mathrm{sec}$ each at $95^{\circ} \mathrm{C}$, $5 \mathrm{sec}$ at $55^{\circ} \mathrm{C}$, and $30 \mathrm{sec}$ at $70^{\circ} \mathrm{C}$, were conducted. The data obtained were analyzed using the comparative-cycle threshold method, and were normalized using the $\beta$-actin expression value. Melting curves were generated for each PCR reaction to ensure the purity of the amplification product.

\section{Statistical analyses}

The data are presented as mean \pm SEM. Two-tailed Student's $t$ tests were used to identify the significant differences $(P<0.05)$ between the means for $\mathrm{CD}$ and $\mathrm{CD}+\mathrm{M}$ rats.

\section{Results}

Body weight gain and visceral fat-pad weights

Rats fed the high-fat CD attained $463 \pm 23.1 \mathrm{~g}$ of cumulative body weight gain in 9 weeks. Dietary supplementation of the mixture composed of G. cambogia, soypeptide and L-carnitine for 9 weeks significantly reduced the body weight gain compared to the value for the $\mathrm{CD}$ rats (18\% reduction) (Table 1$)$. The food efficiency ratio of the rats in the $\mathrm{CD}+\mathrm{M}$ group was significantly lower than the value for the $\mathrm{CD}$ rats $(P<0.05)$.

The relative weights of the visceral fat deposits were smaller in the $\mathrm{CD}+\mathrm{M}$ rats than in the $\mathrm{CD}$ rats (Table 1). The epididymal, perirenal, retroperitoneal, and mesenteric fat-pad weights were reduced by $18 \%(P>0.05), 33 \%$ $(P<0.01), \quad 16 \% \quad(P<0.05)$, and $15 \% \quad(P<0.05)$,
Table 1 Body weight gain, visceral fat-pad weight, and serum and hepatic biochemistry of rats fed the high-fat control diet (CD) or the mixture-supplemented diet $(\mathrm{CD}+\mathrm{M})$ for 9 weeks. Values are mean \pm SEM, $n=10$

\begin{tabular}{|c|c|c|}
\hline & $\mathrm{CD}$ & $\mathrm{CD}+\mathrm{M}$ \\
\hline Body weight gain (g/9 weeks) & $463 \pm 23.3$ & $385 \pm 15.4^{*}$ \\
\hline Food efficiency ratio ${ }^{a}$ & $0.27 \pm 0.009$ & $0.24 \pm 0.007 *$ \\
\hline \multicolumn{3}{|l|}{$\begin{array}{l}\text { Visceral fat-pad weight } \\
\text { (g/100 g body weight })\end{array}$} \\
\hline Epididymal & $2.86 \pm 0.27$ & $2.35 \pm 0.10$ \\
\hline Perirenal & $0.85 \pm 0.05$ & $0.57 \pm 0.04 * *$ \\
\hline Retroperitoneal & $3.33 \pm 0.22$ & $2.79 \pm 0.05^{*}$ \\
\hline Mesenteric & $2.29 \pm 0.10$ & $1.94 \pm 0.03 *$ \\
\hline Total & $9.33 \pm 0.58$ & $7.65 \pm 0.15^{*}$ \\
\hline \multicolumn{3}{|l|}{ Serum } \\
\hline Total cholesterol (mmol/l) & $4.43 \pm 0.58$ & $2.63 \pm 0.24^{*}$ \\
\hline HDL cholesterol (mmol/l) & $1.21 \pm 0.09$ & $1.03 \pm 0.06$ \\
\hline $\begin{array}{l}\text { VLDL + LDL cholesterol }{ }^{\mathrm{b}} \\
\quad(\mathrm{mmol} / \mathrm{l})\end{array}$ & $2.55 \pm 0.32$ & $1.60 \pm 0.21 *$ \\
\hline Triglyceride (mmol/l) & $0.37 \pm 0.04$ & $0.32 \pm 0.04$ \\
\hline Free fatty acid (mmol/l) & $0.60 \pm 0.04$ & $0.35 \pm 0.02 * * *$ \\
\hline Glucose (mmol/l) & $10.4 \pm 0.58$ & $8.07 \pm 0.44 * *$ \\
\hline Insulin (pmol/1) & $641 \pm 14.4$ & $178 \pm 44.5^{*}$ \\
\hline C-peptide (pmol/l) & $2,047 \pm 226$ & $832 \pm 134 * *$ \\
\hline Leptin (ng/ml) & $11.0 \pm 1.57$ & $6.09 \pm 0.84 *$ \\
\hline \multicolumn{3}{|l|}{ Liver } \\
\hline $\begin{array}{l}\text { Liver weight } \\
\qquad(\mathrm{g} / 100 \mathrm{~g} \text { of body weight) }\end{array}$ & $5.01 \pm 0.18$ & $4.36 \pm 0.09 * *$ \\
\hline Cholesterol ( $\mu \mathrm{mol} / \mathrm{g}$ of liver) & $16.4 \pm 0.42$ & $14.9 \pm 0.32 *$ \\
\hline Triglyceride $(\mu \mathrm{mol} / \mathrm{g}$ of liver $)$ & $17.7 \pm 0.31$ & $16.6 \pm 0.30^{*}$ \\
\hline
\end{tabular}

${ }^{a}$ Body weight gain for experimental period (g) / food intake for experimental period $(\mathrm{g})$

${ }^{\mathrm{b}}$ LDL + VLDL cholesterol $=$ total cholesterol-HDL cholesterol

$* P<0.05 ; * * P<0.01 ; * * * P<0.001$

respectively, in rats that had been fed the $\mathrm{CD}+\mathrm{M}$ compared to the $\mathrm{CD}$ rats. The mixture-induced reduction in the accumulation of visceral fat mass was most significant in the perirenal fat tissue compared with visceral fat tissues located elsewhere. The total weight of visceral fat deposits pooled from the four different locations was $18 \%$ lower in the $\mathrm{CD}+\mathrm{M}$ rats than in the $\mathrm{CD}$ rats $(P<0.05)$.

Blood and hepatic biochemistry

The serum total and LDL + VLDL cholesterol concentrations were 41 and $37 \%$ lower, respectively, in rats fed the $\mathrm{CD}+\mathrm{M}$ compared to those of the $\mathrm{CD}$ rats $(P<0.05)$ (Table 1). Dietary supplementation of the mixture to rats fed the HFD significantly decreased the serum free fatty acid concentration (42\% reduction, $P<0.001)$ without 
significantly altering the serum triglyceride concentration. Dietary supplementation of the mixture for 9 weeks also significantly reduced the hepatic cholesterol and triglyceride concentrations in rats fed the HFD. The relative weight of the liver was significantly smaller in the $\mathrm{CD}+\mathrm{M}$ rats than in the $\mathrm{CD}$ rats. Moreover, dietary supplementation of the mixture to rats fed the HFD resulted in significant decreases in the serum concentrations of glucose $(22 \%$ reduction, $P<0.01)$, insulin $(72 \%$ reduction, $P<0.05$ ), c-peptide (59\% reduction, $P<0.01$ ) and leptin (45\% reduction, $P<0.05)$, as summarized in Table 1.

Gene expression profiles in the epididymal adipose tissue

Mixture-induced gene regulation was evaluated using realtime RT-PCR analyses. The expression levels of the leptin, TNF- $\alpha$, and SREBP1c genes in epidydimal fat tissue of rats fed CD + M were 40, 60 and 48\%, respectively, of those found in $\mathrm{CD}$ rats. The PPAR $\gamma$ gene expression in the epididymal fat tissue of $\mathrm{CD}+\mathrm{M}$ rats was $75 \%$ of that found in $\mathrm{CD}$ rats $(P>0.05)$. In contrast, mixture supplementation to the HFD up-regulated expression of the UCP2 gene in the epididymal fat tissue of the rats (1.25fold, $P<0.05$ ). Expression of the resistin and $\mathrm{C} / \mathrm{EBP} \alpha$ genes in the epididymal fat tissue was not significantly affected by the same supplementation in rats fed the HFD (Fig. 1).

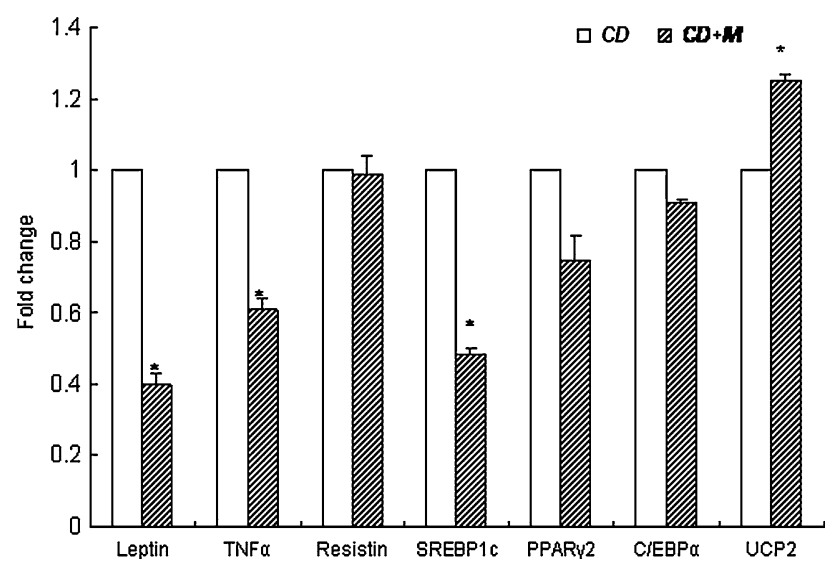

Fig. 1 Gene expression profiles determined by real-time RT-PCR analyses of RNA from epididymal fat tissues of rats fed the high-fat control diet $(\mathrm{CD})$ or the mixture-supplemented high-fat diet $(\mathrm{CD}+$ $\mathrm{M})$. Results were normalized to $\beta$-actin mRNA expression. The mRNA levels of rats fed $C D+M$ were expressed as the fold change compared to $\mathrm{CD}$ rats. Values are means \pm SEM of duplicate analyses of RNA samples pooled from ten rats

\section{Discussion}

We have previously observed that a HFD (40\% fat calories), with identical composition to the high-fat $\mathrm{CD}$ used in the current study, produces obese conditions in rats that mimic human obesity. HFD-induced obesity rats weigh $55 \%$ more and accumulate $85-133 \%$ more visceral fats, depending on the location, than normal rats. These obese rats acquire dyslipidemia, fatty liver, insulin resistance, and hyperleptinemia along with over-expression of leptin, TNF- $\alpha$, resistin, PPAR $\gamma 2$, C/EBP $\alpha$, and SREBP1c genes in epididymal adipose tissue (manuscript submitted). An antiobesity effect of a mixture composed of the G. cambogia extract, soy peptide and L-carnitine was observed in the HFD-induced obesity rat model. The results from the present study clearly demonstrate that the mixture significantly reduces the accumulation of visceral fat mass and effectively lowers blood and hepatic lipid levels, leading to the improvement of insulin resistance in rats rendered obese by HFD.

The mixture of G. cambogia, soy peptide, and L-carnitine appears to exert its anti-obesity effect via modulation of the metabolic derangement induced by the HFD, and might involve interactions between multiple genes implicated in the process of visceral adiposity and the dietary intervention, rather than by simply suppressing appetite. As supplementation of the mixture to the HFD did not affect the food intake of the animals (data not shown), it is unlikely that the anti-obesity effect of the mixture results from a refusal to ingest the food.

Decreases in the levels of serum and hepatic lipids, such as total cholesterol, VLDL + LDL cholesterol, and free fatty acid, in rats fed $C D+M$ compared to those for $C D$ rats could be attributed to the inhibition of lipid absorption in the gastrointestinal tract. Dietary lipids are absorbed into the bloodstream as chylomicron; triglycerides in these chylomicrons are then digested as fatty acids and glycerol by lipoprotein lipase, and are eventually transported and stored in the liver and adipose tissues in the form of triglycerides. The remnants of the chylomicrons are taken up mainly by the liver, and are then transformed into lipoproteins, such as VLDL, which transport triglycerides synthesized in the liver to adipose tissues, and LDL, which transports cholesterol to peripheral tissues [16].

The mixture-induced decreases in serum glucose, insulin, and c-peptide levels of rats fed the HFD may account for the improvement in insulin resistance. Among the various body fat deposits, the visceral fat mass is best correlated to insulin resistance in animal models and humans [5]. Insulin action is markedly impaired in individuals with visceral obesity [29], and the removal of visceral fat mass prevents the insulin resistance and glucose intolerance associated with aging [14]. Two groups of 
inflammatory proteins are produced and released by adipose tissue: (1) inflammatory mediators, predominantly IL6 and TNF- $\alpha$ produced by adipose tissue and macrophages, and (2) adipocytokines such as leptin, adiponectin and resistin [1]. Leptin is a fat-derived key regulator of appetite and energy expenditure, and serum leptin concentration is associated with general adiposity [33]. The slight reduction in the fasting blood glucose level (22\% lower) in spite of the marked decrease in serum insulin level ( $72 \%$ lower) in the $\mathrm{CD}+\mathrm{M}$ rats compared to levels in $\mathrm{CD}$ rats indicates improved insulin sensitivity in rats fed the mixture. The mixture-induced amelioration of insulin resistance is supported by the down-regulation of leptin and TNF $\alpha$ gene expression in the epididymal adipose tissues of rats fed the mixture (Fig. 1).

Adipocyte growth and differentiation are complex processes that are characterized by many changes in cell morphology, hormone sensitivity, and expression of genes controlling lipogenesis and lipolysis [10]. Several transcription factors, such as members of the PPAR $\gamma 2$, C/EBPs, and SREBP1c family, act cooperatively and sequentially to trigger the terminal adipocyte differentiation program [9, 11]. $\operatorname{PPAR} \gamma$ is an adipocyte-specific transcription factor that appears to promote adipocyte differentiation and to control the expression of several fat-specific genes [31]. The C/EBP proteins that are also important in adipogenesis are expressed at high levels in adipose tissues and are induced during adipogenesis [11]. $\mathrm{C} / \mathrm{EBP} \alpha$, in powerful synergy with PPAR $\gamma 2$, promotes the terminal differentiation of preadipocytes [27]. SREBP1c controls the production of endogenous ligands for $\operatorname{PPAR} \gamma$ as a mechanism for coordinating the actions of these adipogenic factors [9]. The down-regulation of SREBP1c and PPAR $\gamma 2$ gene expression in the epididymal fat tissues of rats given $\mathrm{CD}+\mathrm{M}$ may explain the mixture-induced regulation of adipocyte metabolism and its differentiation process. In brown and white adipose tissues, the properties of UCP2 appear to be suited to the regulation of fuel metabolism [32]. Most animal models show up-regulation of UCP2 and/or UCP3 by HFDs, although this has not been universally observed. Up-regulation of UCP expression depends on the strain and tissue type. A high fat diet increased UCP3 mRNA expression in the skeletal muscle of C57BL/6J mice [15] and rats [24] but increased UCP2 expression only slightly in white adipose tissue of AKR mice and not at all in C57BL/6J mice [15] or in rats [24].

Hydroxy citric acid is a potent competitive inhibitor of ATP citrate lyase (EC 4.1.3.8) [34], which is an extramitochondrial enzyme catalyzing the cleavage of citrate to oxaloacetate and acetyl-CoA. This inhibitory action of $\mathrm{HCA}$ reduces the acetyl-CoA pool, thus limiting the availability of the two-carbon units required for the initial steps of fatty acid and cholesterol biosynthesis [6, 34]. The reduction in the acetyl-CoA pool is thought to decrease the concentration of malonyl-CoA, thus resulting in the suppression of body fat accumulation through stimulation of carnitine palmitoyltransferase I activity and promotion of fatty acid oxidation [21]. G. cambogia extracts have potential as anti-obesity agents [19, 21, 22], and reduce the expression of the major adipogenic transcription factor, $\mathrm{C} /$ $\mathrm{EBP} \alpha$, in 3T3-L1 cells [26] and that of $\operatorname{PPAR} \gamma$, a nuclear hormone receptor involved in regulation of adipogenesis during differentiation [36].

L-Carnitine is an essential cofactor in the transport of long-chain fatty acids, such as acylcarnitine esters, across the inner mitochondrial membrane for subsequent fat degradation and energy production [35]. L-Carnitine also functions in processes such as $\beta$-oxidation of long-chain fatty acids in peroxisomes, and the transfer of acetyl and other short-chain acyl groups from peroxisomes to mitochondria [30]. Another role of L-carnitine is shuttling shortchain fatty acids from inside the mitochondria to the cytosol. Therefore, L-carnitine is responsible for maintaining the energy metabolism of the whole body [38]. Expression of both PPAR $\gamma$ and adipose-specific fatty acidbinding protein ( $\mathrm{aP} 2)$, which are involved in adipogenesis, was found to be down-regulated by L-carnitine in 3T3-L1 adipocytes [25].

In the present study, the levels of leptin, TNF- $\alpha$, and SREBP1c mRNA in epididymal adipose tissue were found to be decreased significantly in rats supplemented with the mixture. In conclusion, a mixture composed of G. cambogia aqueous extract, soy peptide and L-carnitine attenuated visceral fat accumulation and improved insulin resistance in a rat model with HFD-induced obesity, possibly through down-regulation of leptin, TNF- $\alpha$, SREBP1c, and PPAR $\gamma 2$ gene expression in epididymal adipose tissue.

Acknowledgments This work was supported by the Project of BioFood Research (\# M10510130001-06N1013-00110) from the Korea Science and Engineering Foundation (KOSEF) under the Ministry of Science and Technology in Korea, and by the Brain Korea 21 Project, Yonsei University.

\section{References}

1. Alam I, Lewis K, Stephens JW, Baxter JN (2006) Obesity, metabolic syndrome and sleep apnoea: all pro-inflammatory states. Obes Rev 8:119-127

2. Anderson JW, Smith BM, Washnock CS (1990) Cardiovascular and renal benefits of dry bean and soybean intake. Am J Clin Nutr 70:464-474

3. Anderson JW, Johnstone BM, Cook-Newell ME (1995) Metaanalysis of effects of soy protein intake on serum lipids in humans. N Engl J Med 333:276-282

4. Attele AS, Zhou YP, Xie JT, Wu JA, Zhang L, Dey L, Pugh W, Rue PA, Polonsky KS, Yuan CS (2002) Anti-diabetic effects of Panax ginseng berry extract and the identification of an effective component. Diabetes 51:1851-1858 
5. Axen KV, Dikeakos A, Sclafani A (2003) High dietary fat promotes syndrome $X$ in nonobese rats. J Nutr 133:2244-2249

6. Berkhout TA, Havekes LM, Pearce NJ, Groot PHE (1990) The effect of (-)-hydroxycitrate on the activity of the low-densitylipoprotein receptor and 3-hydroxy-3-methylglutaryl-CoA reductase levels in the human hepatoma cell line Hep G2. Biochem J 272:181-186

7. Bhathena SJ, Velasquez MT (2002) Beneficial role of dietary phytoestrogens in obesity and diabetes. Am J Clin Nutr 76:11911201

8. Bouchard C, Tremblay A (1997) Genetic influences on the response of body fat and fat distribution to positive and negative energy balances in human identical twins. J Nutr 127:943-947

9. Brown MS, Goldstein JL (1997) The SREBP pathway: regulation of cholesterol metabolism by proteolysis of a membrane-bound transcription factor. Cell 89:331-340

10. Brun RP, Kim JB, Hu E, Spiegelman MB (1997) Peroxisome proliferator-activated receptor gamma and the control of adipogenesis. Curr Opin Lipidol 8:212-218

11. Fajas L, Fruchart JC, Auwerx J (1998) Transcriptional control of adipogenesis. Curr Opin Lipidol 10:165-173

12. Folch J, Less M, Sloane Stanley GH (1957) A simple method for the isolation and purification of total lipids from animal tissues. J Biol Chem 226:497-509

13. Food Drug Administration (1999) Food labeling health claims; soy protein and coronary heart disease. Food and drug administration, HHS. Final rule. Fed Regist 64:57700-57733

14. Gabriely I, Ma XH, Yang XM, Atzmon G, Rajala MW, Berg AH, Scherer P, Rossetti L, Barzilai N (2002) Removal of visceral fat prevents insulin resistance and glucose intolerance of aging: an adipokine-mediated process? Diabetes 51:2951-2958

15. Gong DW, He Y, Reitman ML (1999) Genomic organization and regulation by dietary fat of the uncoupling protein 3 and 2 genes. Biochem Biophys Res Commun 256:27-32

16. Guyton AC, Hall JE (1996) In: Guyton AC (ed) Textbook of medical physiology. Saunders, Philadelphia, pp 869-899

17. Han LK, Xu BJ, Kimura Y, Zheng Y, Okuda H (2000) Platycodi radix affects lipid metabolism in mice with high fat diet-induced obesity. J Nutr 130:2760-2764

18. Han LK, Gong XJ, Kawano S, Saito M, Kimura Y, Okuda H (2005) Antiobesity actions of Zingiber officinale Roscoe. Yakugaku Zasshi 125:213-217

19. Hasegawa N (2001) Garcinia extract inhibits lipid droplet accumulation without affecting adipose conversion in 3T3-L1 cells. Phytother Res 15:172-173

20. Heymsfield SB, Allison DB, Vasselli JR, Pietrobelli A, Greenfield D, Nunez C (1998) Garcinia cambogia (hydroxycitric acid) as a potential antiobesity agent. JAMA 280:1596-1600

21. Ishihara K, Oyaizu S, Onuki K, Lim K, Fushiki T (2000) Chronic (-)-hydroxycitrate administration spares carbohydrate utilization and promotes lipid oxidation during exercise in mice. J Nutr 130:2990-2995

22. Jena BS, Jayaprakasha GK, Singh RP, Sakariah KK (2002) Chemistry and biochemistry of (-)-hydroxycitric acid from Garcinia. J Agric Food Chem 50:10-22
23. Junbao Y, Long J, Jiangbi W, Yonghui D, Tianzhen Z, Songyi Q, Wei L (2004) Inhibitive effect of Semen Cassiaem on the weight gain in rats with nutritive obesity. Zhong Yao Cai 27:281-284

24. Kusunoki M, Tsutsumi K, Iwata K, Yin W, Nakamura T, Ogawa $\mathrm{H}$, Nomura T, Mizutani K, Futenma A, Utsumi K, Miyata T (2005) NO-1886 (ibrolipim), a lipoprotein lipase activator, increases the expression of uncoupling protein 3 in skeletal muscle and suppresses fat accumulation in high-fat diet-induced obesity in rats. Metabolism 54:1587-1592

25. Lee MS, Lee HJ, Lee HS, Kim Y (2006) L-carnitine stimulates lipolysis via induction of the lipolytic gene expression and suppression of the adipogenic gene expression in 3T3-L1 adipocytes. J Med Food 9:468-473

26. Lin FT, Lane MD (1994) CCAAT/enhancer binding protein alpha is sufficient to initiate the 3T3-L1 adipocyte differentiation program. Proc Natl Acad Sci USA 91:8757-8761

27. Mandrup S, Lane MD (1997) Regulating adipogenesis. J Biol Chem 272:5367-5370

28. Nakamura T, Tokunaga K, Shimomura I, Nishida M, Yoshida S, Kotani K, Islam AHMW, Keno Y, Kobatake T, Nagai Y, Fujioka S, Tarui S, Matuzawa Y (1994) Contribution of visceral fat accumulation to the development of coronary artery disease in non-obese men. Atherosclerosis 107:239-246

29. O'Shaughnessy IM, Myers TJ, Stepniakowski K, Nazzaro P, Kelly TM, Hoffmann RG, Egan BM, Kissebah AH (1995) Glucose metabolism in abdominally obese hypertensive and normotensive subjects. Hypertension 26:186-192

30. Rebouche CJ, Seim H (1998) Carnitine metabolism and its regulation in microorganisms and mammals. Annu Rev Nutr 18:39-61

31. Rousseau V, Becker DJ, Ongemba LN, Rahier J, Henquin JC, Brichard SM (1997) Developmental and nutritional changes of ob and PPAR gamma 2 gene expression in rat white adipose tissue. Biochem J 321:451-456

32. Saleh MC, Wheeler MB, Chan CB (2002) Uncoupling protein-2: evidence for its function as a metabolic regulator. Diabetologia 45:174-87

33. Staiger H, Haring HU (2005) Adipocytokines: fat-derived humoral mediators of metabolic homeostasis. Exp Clin Endocrinol Diabetes 113:67-79

34. Sullivan AC (1977) Reactivity and inhibitor potential of hydroxycitrate isomers with citrate synthetase, citrate lyase, and ATP citrate lyase. J Biol Chem 252:7583-7590

35. Tein I, Bukovac SW, Xie-ZW (1996) Characterization of the human plasmalemmal carnitine transporter in cultured skin fibroblasts. Arch Biochem Biophys 329:145-155

36. Tontonoz P, Hu E, Graves RA, Budavari AI, Spiegelman BM (1994) mPPAR gamma 2: tissue-specific regulator of an adipocyte enhancer. Genes Dev 8:1224-1234

37. Velasquez MT, Bhathena SJ (2001) Dietary phytoestrogens a possible role in renal disease protection. Am J Kidney Dis 37:1056-1068

38. Wutzke KD, Lorenz H (2004) The effect of L-carnitine on fat oxidation, protein turnover, and body composition in slightly overweight subjects. Metabolism 53:1002-1006 